\title{
Strengthening of Vulnerable RC Moment Resisting Frames Using Direct Internal Connection of X-Steel Bracing
}

\author{
Siavash Sadeghinezhad ${ }^{1}$, Ali Kheyroddin ${ }^{1 *}$, Alireza Mortezaei ${ }^{1}$ \\ ${ }^{1}$ Department of Civil Engineering, Semnan Branch, Islamic Azad University, 37111-35131 Semnan, Iran \\ * Corresponding author, e-mail: kheyroddin@semnan.ac.ir
}

Received: 09 August 2020, Accepted: 14 July 2021, Published online: 02 August 2021

\begin{abstract}
Non-ductile reinforced concrete frames are commonly found in older buildings in many parts of the world. These structures are designed for gravity loads, have limited lateral strength and ductility, are prone to excessive one-way lateral movement and soft-story mechanism. This paper focuses on the retrofit of an existing reinforced concrete frame, using steel X-braces by direct internal connection method. The main purpose is the analytical study of general behavior and response of large-scale vulnerable frames. An experimental study was used to validate the numerical modelling performed in ABAQUS. Next, the base models were retrofitted with X-braces and four proposed direct internal connection methods. Additionally, in separate parametric studies, the effect of frame-type, bracing cross-section dimensions and gusset plate shape were investigated. The results indicated that the stiffness, bearing capacity and absorbed energy of the reinforced concrete frame by using steel X-braces increases up to $4,2.3$ and 1.5 times, respectively. Moreover, bracing acts like the first defense system against lateral loads, such as structural fuse with its yield, increases the amount of energy dissipation. It also removes the plastic hinges by reducing the ultimate displacement and stress of lateral load in the panel zone.
\end{abstract}

Keywords

reinforced concrete frame, steel X-brace, strengthening, finite element analysis, steel jacket

\section{Introduction}

For a variety of reasons, existing structures may need to be upgraded. This improvement includes the restoration of structures damaged by earthquakes and other factors or the retrofit of an undamaged vulnerable structure that was designed and built with or without old-edited loading codes (ANSI ${ }^{1}$, etc.). Undamaged buildings that do not have adequate resistance for various reasons. These reasons may include changing the code rules, changing the use of the building and adding the number of stories. In any case, the resistance and stiffness must be increased to adapt to new conditions and satisfy the code requirements. Moreover, reinforced concrete $(\mathrm{RC})$ buildings may also have inherent vulnerabilities for several reasons, the most important of which is site construction. Over the years, various methods have been studied in the local and overall retrofit of $\mathrm{RC}$ frames, some of which are the coating of columns

1 American National Standards Institute and beams with steel jackets and composite sheets (FRP) ${ }^{2}$, addition of RC infilled frames (shear-wall), concentric or eccentric steel bracing, placed internally or externally, post-tensioned concrete, base isolation, dampers and etc. Each of these methods can be used to improve the linear and nonlinear behavior of RC frames, taking into account their technical and economic benefits. In recent years, the use of steel braces as an efficient method to strengthen existing $\mathrm{RC}$ frames has received more compliance due to various reasons such as transmissibility and lower cost. In weak reinforced concrete frames, which are quickly removed from the system in an earthquake and have an instability hysteresis curve, this additive system causes the system to double and modify the behavior and stability of the curve [1]. The steel brace is connected to the reinforced concrete frame in two ways: direct and indirect. In the indirect method, the braces are placed inside

2 Fiber Reinforced Polymer 
a steel frame and the steel frame is connected to the reinforced concrete frame. This can be done in two ways, in the first method; in the smooth and flat members concrete surface, the steel frame is connected directly to the reinforced concrete frame with adhesive resin or epoxy. In the second method, first, a gap is created between the concrete and steel frame and a number of bolts or dowel reinforcement are planted inside the beam and column. A number of shear keys or reinforcements are also welded to the steel frame. It then placed in a spiral reinforcement and filled with grout or expandable mortar in the gap finally.

In the direct connection method, the steel brace is connected directly to the reinforced concrete frame. This method can be applied in two ways too: using plate and bolts, as well as using jacket curbs. According to researchers, the direct method is superior to the indirect one in terms of architecture, computation, execution, cost and more coordination in seismic behavior with the base RC frame; but of course, the sensitivity of joints and increasing the effect of bracing slippage in them, are also a few shortcomings [2].

In this paper, aims to investigate the effect of direct internal connection of X-steel bracing in improving the local and overall behavior of existing vulnerable $\mathrm{RC}$ frames, has been evaluated four different direct internal connection methods of X-brace, to a large vulnerable RC moment resistant frame, capable of a soft-story mechanism potentially. Vulnerability refers to instances when the RC frame has problems with vertical and lateral displacement under gravity and lateral loads. For example, sheer weakness and the creation of plastic hinges in the connections of RC structure with moment resistant frame system, due to the lack or insufficiency of column stirrup in the panel zone, or reduced height beam due to elimination of the beam hanger.

Therefore, an experimental study on a one-story - onespan RC frame that represents the condition of old buildings in Thailand and was designed based on old codes has been selected for validation. This RC frame, which is vulnerable to the soft-story mechanism and does not satisfy strong column-weak beam criteria, due to the weakness of the columns and the panel zone, is numerically modelled in ABAQUS software and then strengthened with a steel X-bracing system. To connect these compressive and tensile braces to the concrete members, steel jackets have been used externally. At the same time, by coating the columns by cover plates in one connection instances, they have been strengthened to be better equipped to respond to overloads and prevent short-column mechanism.
Nowadays, the use of steel plates for local strengthened of RC members has been compliant, due to the fast implementation, minimal damage to the existing structure and small changes required in the dimensions of the sections. However, problems such as undesirable shear failure, difficult transporting, corrosion and the lip to lip connections have limited its efficiency.

One of the important points in using steel braces to strengthen a RC structure is how to choose its dimensions to match the performance goals required by the composite structure. In this study, experimental-based behaviors performed on non-ductile RC frames with and without braces have been used to provide accurate analytical models. Initially, two separate parametric studies provide strong column-weak beam criteria, once reduced the height of the beam and once again more reinforced the columns. Secondly, the effect of the gusset dimension has been evaluated in width-span frames. Finally, to investigate the brace sections effect, the results of three cross-section areas are compared. To study and analysis the behavior, general response and failure mode of existing structures and performance-based design (PBD), a large number of nonlinear pushover analysis were performed under monotonic incremental lateral load on bare $\mathrm{RC}$ and braced frames. After which, they were compared in terms of resistance, stiffness, ductility and energy dissipation parameters.

\section{Past studies}

Many researchers have worked on strengthening $\mathrm{RC}$ frames using steel braces and retrofitting them locally by coating steel plates. Between 1988-1990, Sekiguchi et al. [3], Badoux and Jirsa [4] reported practical examples of retrofitting using these methods. In 1992, Pincheira and Jirsa [5] evaluated the resistance and seismic response of RC buildings strengthened with ductile steel braces and noted the stability and wideness of hysteresis loops of this type of composite frame. From 2000, Kheyroddin et al. [6-10] have conducted several experimental and theoretical studies on the behaviour of $\mathrm{RC}$ frames strengthened by $\mathrm{X}$, concentric, eccentric and buckling restrained steel braces, with and without the use of steel jackets and formable elements. In 2003, Maheri et al. conducted experimental studies on $\mathrm{X}$ and knee-braced RC buildings to evaluate seismic parameters and the possibility of designing connections between braces and frames [11-14]. Massumi and Tasnimi [15] verify the applicability of the direct connection method of steel braces to RC frames with the experimental study. In 1995, Nateghi-A [16] used the direct 
connection technique to retrofit an existing eight-story building. In 1997, Maheri and Sahebi [17] provided a direct connection method without steel frame between brace and $\mathrm{RC}$ frame. They proposed a direct internal bracing method to retrofit existing buildings as well as a shear resistant element in the design of new structures. Using scaled models of directly X-braced RC frames, they found that the shear capacity of the frame could be up to triple. In 2001, a numerical study was carried out by Ghobarah and Abou Elfath on the direct internal concentric and eccentric braces connections in non-ductile RC buildings, which shows a desirable seismic performance of them [18, 19]. Tagawa et al. [20] experimentally tested a RC frame strengthened with K-brace and concluded that the capacity of the composite frame could be equivalent to the sum of the component's capacities. In 2007, during an experimental study on RC moment resistant frames retrofitted with concentric steel braces, Youssef et al. [21] found a higher strength than the prototype. In addition, despite the $35 \%$ reduction in total weight of rebar compared to the RC frame, the braced frame had a more suitable seismic performance, hysteresis behavior and energy dissipation. Overview of the research implies that strengthening with steel braces has positive results. At the same time, the architectural considerations that provide suitable connections between the steel brace and the $\mathrm{RC}$ frame are common concerns.

\section{Model validation}

Since the main purpose of this paper is to investigate the linear and nonlinear behavior of vulnerable non-ductile $\mathrm{RC}$ frames designed according to the old codes, the same experimental study has been selected to verify the modelling accuracy.

\subsection{Detail of experimental study}

This sample, which is related to a large-scale, one-story - one-span, non-ductile flat RC frame, was tested by Khampanit et al. [1] in 2014 at King Mongkut University in Bangkok, designed according to old codes by the GLD ${ }^{3}$ method. In this experimental specimen, the small size of the columns relative to the beam, as well as defect reinforcement at the beam-column panel zone, have made the structure vulnerable to the soft-story mechanism. The test specimen was designed to represent the $\mathrm{RC}$ frame in the first story of a typical school building in Thailand. The test specimen was designed such that key structural indices were similar to those of the prototype frame. Structural indices are numerical indicators, such as flexural-to-shearstrength ratio, longitudinal and shear reinforcement ratios, shear-span-to-depth ratio, and average axial and shear stresses, which can be used to assess the behavior of structural members. Based on the structural indices of the prototype frame, the size and amount of reinforcement of the test specimens could be selected. The final specimen was approximately half-scale [1]. The material properties of the beam and column are given in Table 1. The test setup and the details of the specimen are shown in Fig. 1. As the arrangement of the bars is shown in this figure, longitudinal bars pass through the joints and no stirrups are provided in the joints.

Table 1 Average material properties of specimen

\begin{tabular}{cccccccc}
\hline \multicolumn{2}{c}{ Concrete } & \multicolumn{3}{c}{ Reinforcement steel } & \multicolumn{2}{c}{ Braces } \\
\hline$f_{c}^{\prime}(\mathrm{MPa})$ & $f_{t}^{\prime}(\mathrm{MPa})$ & \multicolumn{2}{c}{$f_{y}(\mathrm{MPa})$} & $f_{u}(\mathrm{MPa})$ & $f_{y}(\mathrm{MPa})$ & $f_{u}(\mathrm{MPa})$ \\
& & $\emptyset_{6}$ & $\emptyset_{8-16-18}$ & $\emptyset_{6}$ & $\emptyset_{8-16-18}$ & & \\
22.5 & 2.25 & 380 & 390 & 469 & 557 & 240 & 370 \\
\hline
\end{tabular}

3 Gravity Load Design
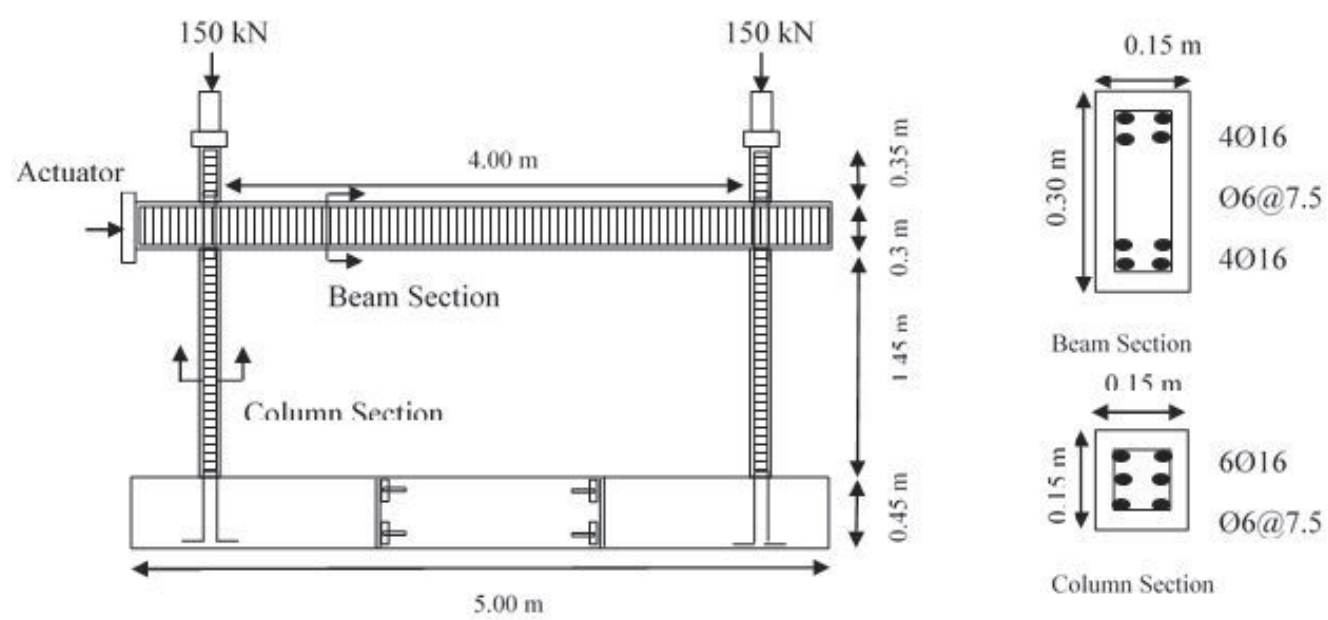

Fig. 1 Dimensions and reinforcement details of the one-span frame tested by Khampanit et al. [1] 
The frame was unified with a strong $\mathrm{RC}$ foundation (there is a rebar cage inside) that is anchored to the strong floor of the laboratory at multiple places; Therefore, rigid support conditions are considered. It was then subjected to quasi-static cyclic loading (the loading history shown in Fig. 2), by a hydraulic actuator with displacement-control method. It is slow cyclic testing with actual time, last many hours. In addition to the lateral load, vertical loads were also applied at the top of the columns using hydraulic jacks to represent the gravity loads. These axial loads were kept constant at $150 \mathrm{kN}$ by manually maintaining the pressure of the hydraulic jacks. Key readings have been made for this specimen. Flexural cracks in the columns were first observed at $29 \mathrm{kN}$ load, and its peak strength was $54.35 \mathrm{kN}$ at $3 \%$ drift. The failure of the columns was primarily governed by bond slip, followed by concrete crushing at the plastic hinge regions, The beam remained almost elastic and without significant cracks. The cracks at the lower ends of the columns are shown in Fig 3. To compare the results, the push of the hysteresis curve is shown in Fig. 4 [1].

\subsection{FEM modeling}

To start the numerical studies, the experimental frame modelled in ABAQUS software, which is a strong engineering simulation program based on $\mathrm{FEM}^{4}$. To ensure the accuracy of nonlinear analysis, this program automatically selects the appropriate load development and convergent tolerances and adjusts them continuously during the analysis. To material failure consideration, three types of cracking can be modelled in this software: Smeared crack, Brittle crack and $\mathrm{CDP}^{5}$. Since the CDP model considers two main assumptions, tensile cracking and compressive crushing in the failure mechanism, it has been used for concrete modelling as a material with elastic strain, tension softening and hardening (Fig. 5). As well as homogeneous wire elements have been used for the rebar and shell element for steel braces and jackets modelling. The specifications of concrete, rebar and steel profiles defined in the software are presented in Table 2.

Concrete, reinforcement bar and steel profiles are meshed by eight-node element and three transitional freedom degrees in each node (C3D8R), truss two-node element (T3D2) and reduced-integration tetrahedral elements (S4R) respectively. By performing mesh sensitivity analysis, a converged mesh of $5 \mathrm{~cm}$ was achieved. Three

\footnotetext{
$4 \quad$ Finite Element Method

5 Concrete Damage Plasticity
}

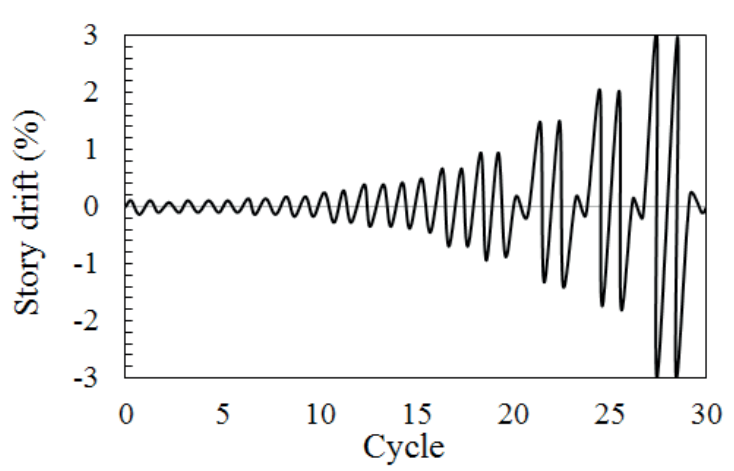

Fig. 2 Loading history applied to experimental specimen [1]

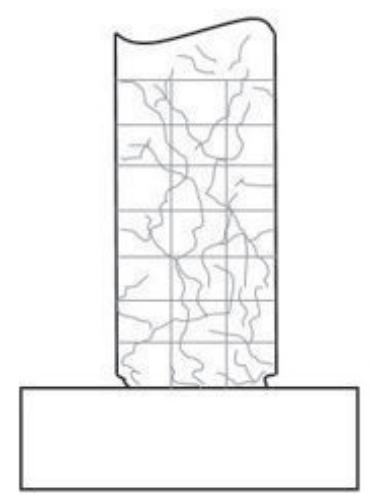

Fig. 3 Crack pattern at 3\% drift in the lower ends of the columns [1]

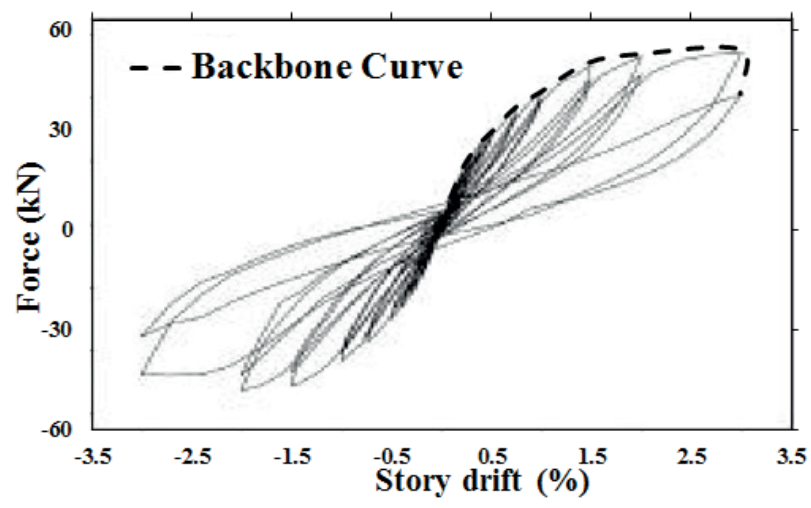

Fig. 4 Load-displacement envelope curve of experimental specimen [1]

mesh states namely coarse $(6 \mathrm{~cm})$, moderate $(5 \mathrm{~cm})$ and fine $(4 \mathrm{~cm})$ were analyzed. The results of the sensitivity analysis are illustrated in Fig. 6. As shown, the top drift ratio is converged in the moderate mesh. On the other hand, the variation in the maximum principal plastic strain maintains even at the fine mesh, of course with a low variable rate. The results of coarse and moderate mesh size are very close to the experimental results and do not differ much. However, by reducing the mesh size, the results of numerical analysis are less than the experimental ones. The assembled and final converged mesh of numerical model is shown in Fig. 7. To match numerical 


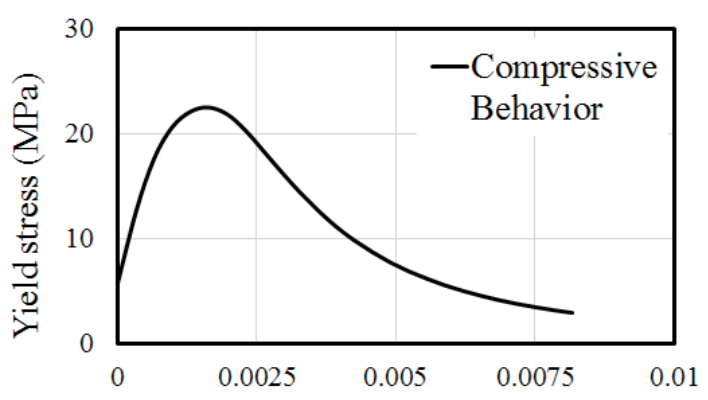

(a)

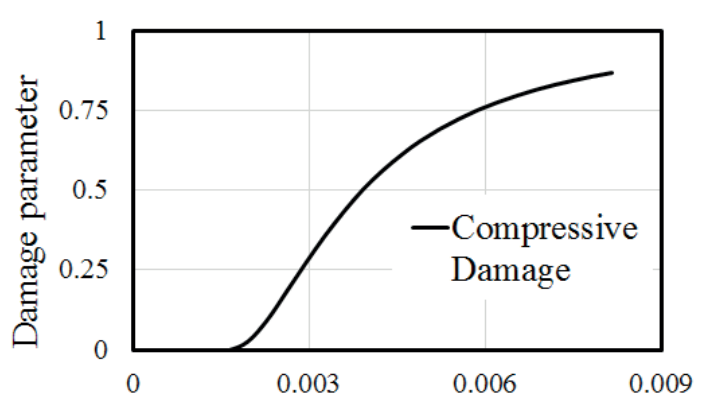

(b)

Inelastic strain

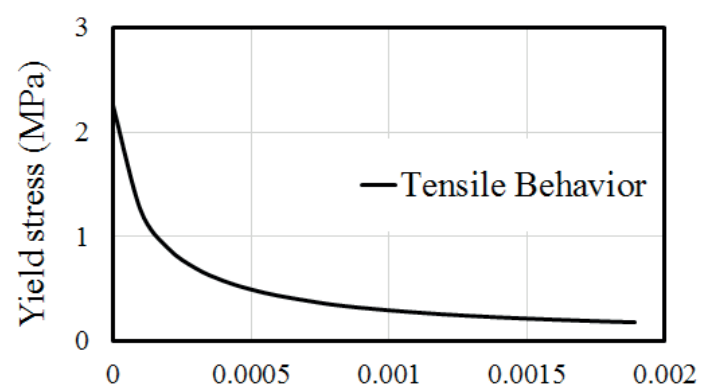

(d)

Cracking strain

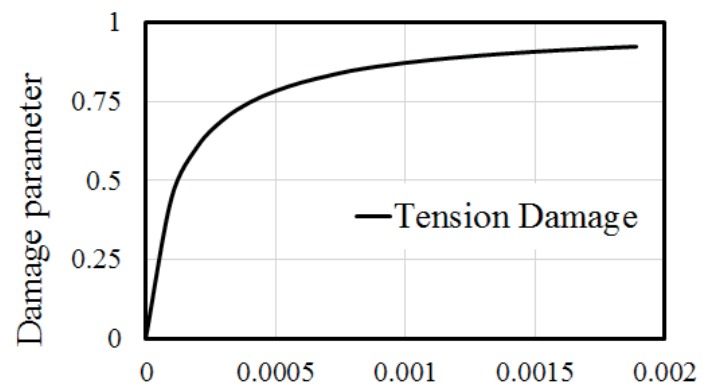

(c)

Cracking strain

Fig. 5 Proposed damage parameter of concrete: Compressive (a) behavior, (b) damage; and Tension (c) damage, (d) behavior

Table 2 Numerical parameters of FEM

\begin{tabular}{|c|c|c|c|c|c|c|c|c|c|}
\hline \multicolumn{10}{|c|}{ Concrete } \\
\hline $\begin{array}{c}W \\
\left(\mathrm{Kg} / \mathrm{m}^{3}\right)\end{array}$ & $\begin{array}{c}E \\
(\mathrm{GPa})\end{array}$ & $\vartheta$ & $\varepsilon_{c r}$ & $\varepsilon_{c u}$ & $\begin{array}{c}\text { Dilation } \\
\text { Angle }\end{array}$ & Eccentricity & $f_{b 0} / f_{c 0}$ & $K$ & $\begin{array}{l}\text { Viscosity } \\
\text { Parameter }\end{array}$ \\
\hline 2400 & 22.65 & 0.2 & 0.0001 & 0.00817 & 35 & 0.1 & 1.16 & 0.667 & 0.0001 \\
\hline \multicolumn{5}{|c|}{ Reinforcement steel } & & \multicolumn{4}{|c|}{ Braces } \\
\hline $\begin{array}{c}W \\
\left(\mathrm{Kg} / \mathrm{m}^{3}\right)\end{array}$ & $\begin{array}{c}E \\
(\mathrm{GPa})\end{array}$ & $\vartheta$ & $\varepsilon_{s y}$ & $\varepsilon_{s u}$ & & $\begin{array}{c}W \\
\left(\mathrm{Kg} / \mathrm{m}^{3}\right)\end{array}$ & $\begin{array}{c}E \\
(\mathrm{GPa})\end{array}$ & $\vartheta$ & \\
\hline 7850 & 200 & 0.3 & 0.002 & 0.2 & & 7850 & 200 & 0.3 & \\
\hline
\end{tabular}

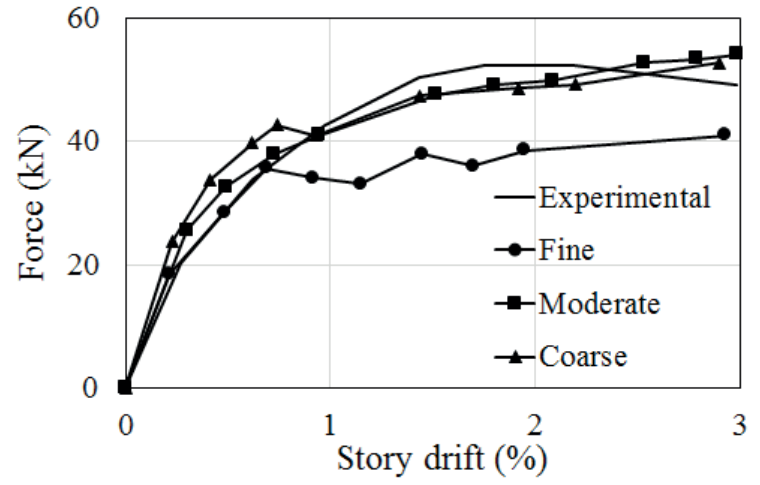

Fig. 6 Concrete mesh sensitivity analysis in numerical model

and experimental circumstances, two-time steps were defined. Firstly, the dead vertical pressure load was applied to the columns and secondly, the live monotonic lateral load was applied with a linear incremental pattern (in a way that matches the cyclic pushover envelopes) as (a)

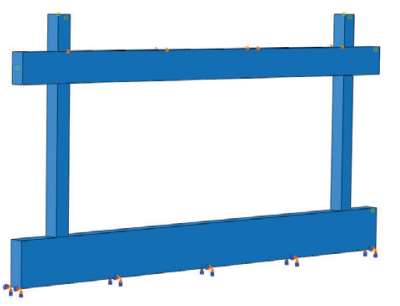

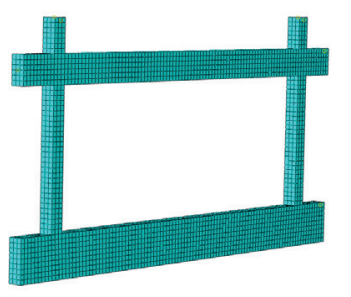

(b)
Fig. 7 Finite element model of experimental specimen in ABAQUS: (a) Assemble and boundary conditions, (b) Final converged mesh

displacement-control method, to the defined referenced point in the lateral surface center of the beam. To simulate and idealize the laboratory support boundary conditions, all the transitional and rotational freedom degrees of footing bottom were fixed; upward of the beam, against out of plane movement were fixed too. The peak strength of this model was $62.25 \mathrm{kN}$ at $3.4 \%$ drift. 


\subsection{Results}

For finite element model validation, the push of the experimental hysteresis curve was compared with the egress load-displacement curve of the numerical model. As it is indicated in Fig. 8, acceptable consistency evidence in their overall behavior. Table 3 shows a $13.5 \%$ average difference between the two curves that confirm the validity of software modelling. It should be noted that the increased stiffness evidenced in the software curve can be related to non-slip and embedded reinforcement modeling, with general adhesion in concrete.

In this model, which will be used as a reference, the first concrete cracking occurs at $19.98 \mathrm{kN}$ load, in the upward of compressive and lower of the tensile side of the columns, and the first yield point of rebar is related to the column longitudinal rebar, at $36.01 \mathrm{kN}$ load in the right pressure column. It should be noted that the yielding force $\left(P_{v}\right)$
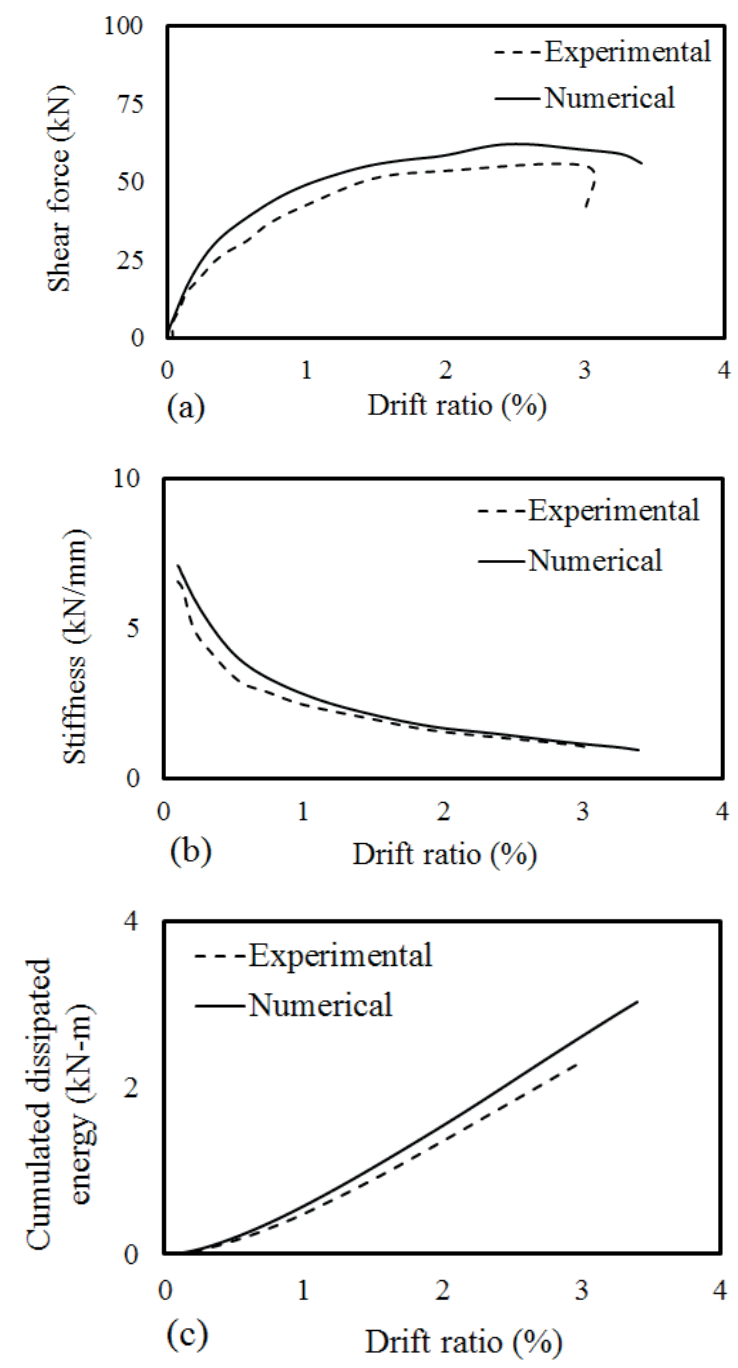

Fig. 8 Calibration the numerical model of RC frame with the experimental results, using the cyclic pushover envelops: (a) Shear force, (b) Stiffness and (c) Cumulated dissipated energy is the load corresponding to when the rebar strain reaches to plastic value. In this frame, the beam rebar did not reach the yield level and the plastic hinges were observed only in the columns. Total compressive and tensile damage of concrete is shown in Fig. 9. As it is indicated, the highest pressure damage occurred in the panel zone, and the highest tensile damage occurred in the column and tensile faces of the beam.

\section{Parametric study}

After modelling verification, parametric studies began with mounted X-braces to the reference RC frame. For this purpose, 27 models, three of them were bare (without brace) and the other with different details of direct internal connection, were subjected to the same monotonic incremental lateral loading history until failure occurred, and nonlinear pushover analyses were carried out. The names and details of the numerical models are given in Table 4.

\begin{tabular}{lccc}
\multicolumn{4}{c}{ Table 3 Comparison of analytical and experimental results } \\
\hline sults & $\begin{array}{c}\text { Maximum Load } \\
(\mathrm{kN})\end{array}$ & $\begin{array}{c}\text { Displacement } \\
(\mathrm{mm})\end{array}$ & $\begin{array}{c}\text { Drift Ratio } \\
(\%)\end{array}$ \\
\hline perimental & 54.35 & 52.5 & 3 \\
merical & 62.25 & 59.48 & 3.4 \\
lerance $(\%)$ & 14 & 13 & 13 \\
lerance & & 13.5 &
\end{tabular}

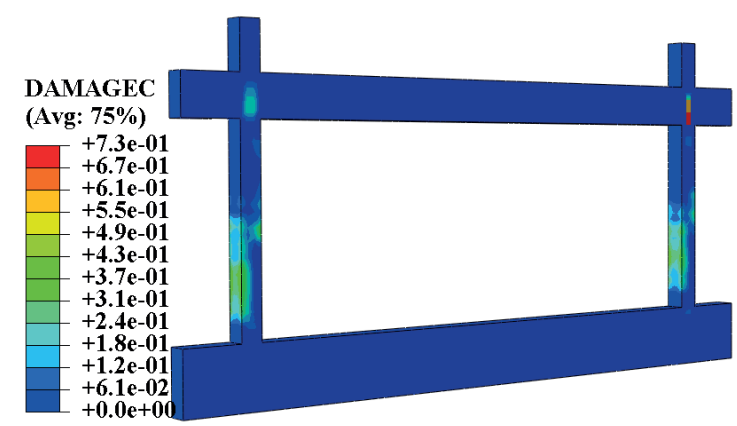

(b)

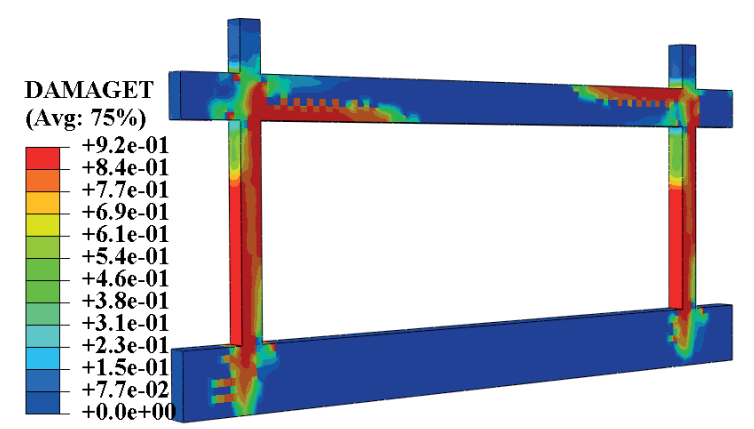

(b)

Fig. 9 Concrete damage contours in numerical model: (a) Compressive $\left(d_{c}\right)$, and (b) Tension $\left(d_{t}\right)$ 
Table 4 Characteristics of the parametric study models

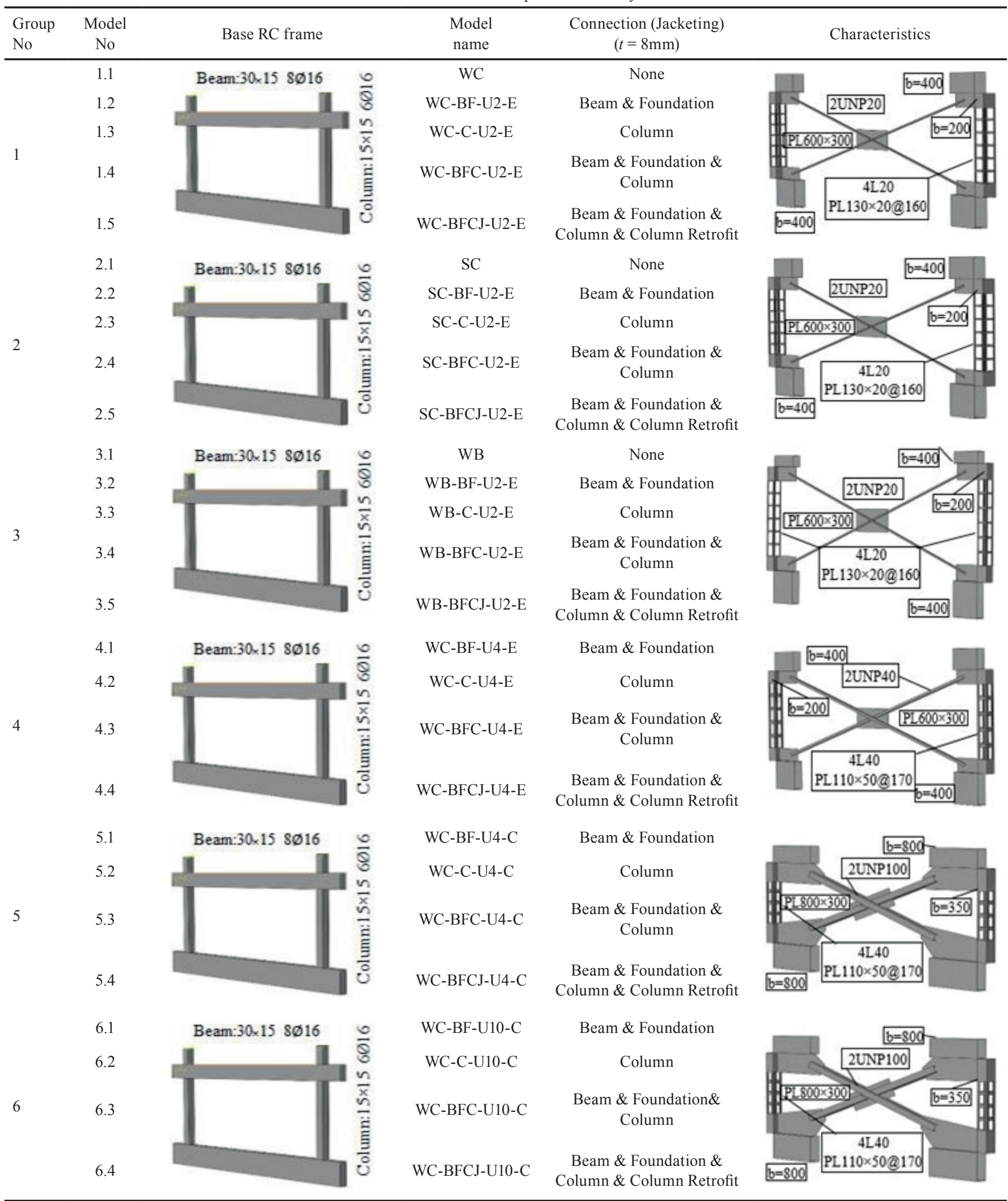

WC: Weak Column, WB: Weak Beam, SC: Strong Column, B: Beam, F: Foundation, C: Column, J: Jacketing, E: Eccentric, C: Concentric 
To satisfy the strong column-weak beam criteria, in the reference RC frame (WC), once reduced the height of the beam and once again more reinforced the columns, which formed two bare frame model that called WB and SC respectively. In each group, four proposed braces to $\mathrm{RC}$ frame connections are evaluated. As shown in Fig. 10, the connections to beam and foundation (BF), columns (C), beam, foundation and columns (BFC) and beam, foundation and columns with columns jacketing (BFCJ). Efficient channel cross-sections have led to evaluated behavior of built-in box-section resulting from the combination of two face to face U-profiles with 144, 576 and $2944 \mathrm{~mm}^{2}$ cross sections area in this study (U2, U4 and U10). These dimensions have been selected taking into account the slenderness of diagonal members in such a way that the lateral resistance and yield drift of braces are at least two and four times the RC frame respectively. Due to the width-span and dimensional ratio of the prototype frame, the concentration of beam, columns and braces require a large gusset and jacket. Therefore, in a separate study, the importance of this design and implementation provision in long frames is evaluated ( $\mathrm{C}$ and $\mathrm{E}$ ). Because of monotonic lateral loading, one compression and one tension diagonal field will be in all braced frames. The yield displacement of the steel brace depends on its orientation and yield strain generally. In defining these elements that are prone to buckling, first the initial defect in buckling analysis is defined and buckling modes are extracted. The material properties and characteristics of steel profiles are presented in Table 1 and 4, respectively. In braced frames, as shown in Fig. 11,

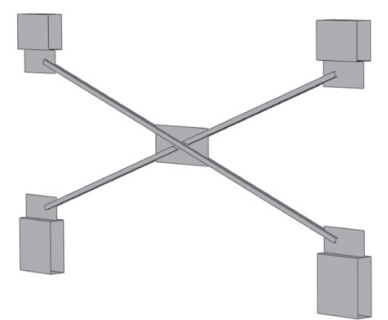

(a)

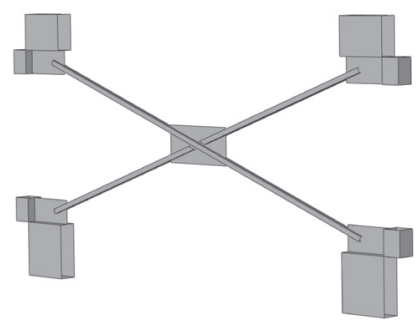

(c)

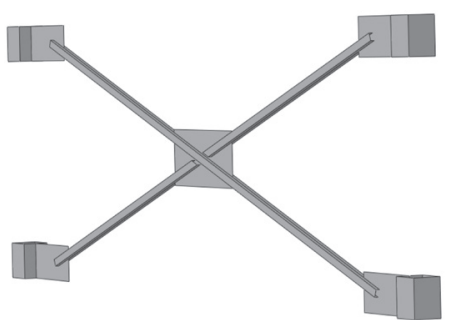

(b)

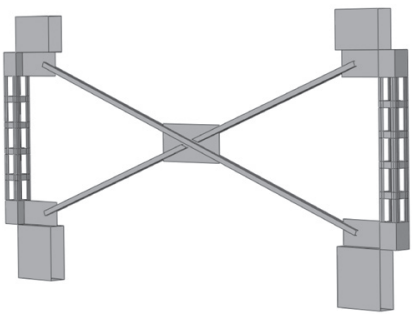

(d)
Fig. 10 Connection's details of braced RC frames: (a) BF, (b) C, (c) BFC and (d) BFCJ the braces are attached by gusset plates to steel jackets made of 2 angle sections and interlock around RC components. The length of the column jackets is 0.14 times of its height $(200 \mathrm{~mm})$ and the length of the beam jackets is 0.1 times of its length $(400 \mathrm{~mm})$ and curb of panel zone situated. Due to the attached form of the steel jacket to the frame members, to prevent slippage and stress focus at the connection zone with concrete surfaces, it was assumed that there is perfect contact and connection between them. Furthermore, experimental observations on the retrofitted $\mathrm{RC}$ joints by this paper authors illustrate that the slippage of steel jacket on concrete surfaces can be ignored $[2,7]$. According to the contents, the results will be categorized and presented in three sections, including the type of RC frame, the gusset plate's dimensions and the brace cross-section area.

\subsection{The Frame type review results}

In this section, three different $\mathrm{RC}$ frames (WC, $\mathrm{SC}$ and $\mathrm{WB}$ ). In the form of three groups 1, 2 and 3, were braced with 2UNP20 sections and the four connection details mentioned above. In all models of this section, the axes of beams, columns and braces are eccentric. In the WC-BFU2-E model, the initial flexural cracks are observed and propagated at $80.63 \mathrm{kN}$ load in the ends of the columns, and the first yield point occurred in the compressive brace, at the brace to beam's gusset intersection. Due to the strain hardening of braces, lateral resistance of the frame increases to about $2 \%$ drift, despite the reinforcement yielding at $101 \mathrm{kN}$ load. With the increased loading, total buckling of the braces occurred at the maximum resistance of $132 \mathrm{kN}$. One of the braces ruptures at this loading level, then the concrete compressive zone of the right column reaches its final strain at $114 \mathrm{kN}$ load. Despite increasing

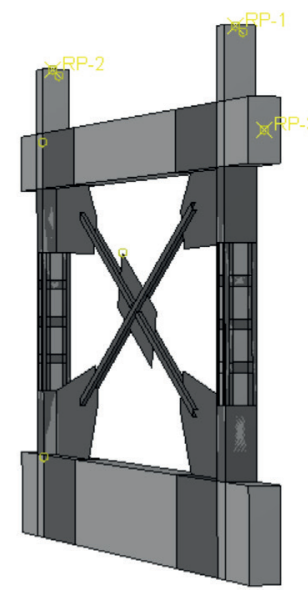

Fig. 11 X-braced RC frame with direct method connections overview 
the stresses in the longitudinal reinforcements of the beam on the jacket curb of this frame relative to the reference one, and approaches the yield limit, but the plastic hinges are still at both ends of the columns. It is observed that with bracing the RC frame, the stiffness, strength and area below the P. $\Delta$ curve increases by about 4,2 and 1.5 times, respectively, and the ultimate displacement decreases by about $50 \%$. In addition, due to the reduction of lateral displacement and increased load transfer from the column to the beam in the braced frame compared to the reference one, concrete tensile damage in the tensile faces of the column decreases and slightly increases in the tensile faces of the beam. Total compressive and tensile damage of concrete is shown in Fig. 12.

Fig. 13 shows the load-displacement curves of the bare frame model with braced ones in the three groups. As it is indicated, the resistance of the braced frames is almost 3 times that of the bare frame. It should be noted that in the $\mathrm{PBD}^{6}$ approach, the lateral strength of the braced frame depends on the brace design details and selected performance. According to Fig. 14, the tangential stiffness of

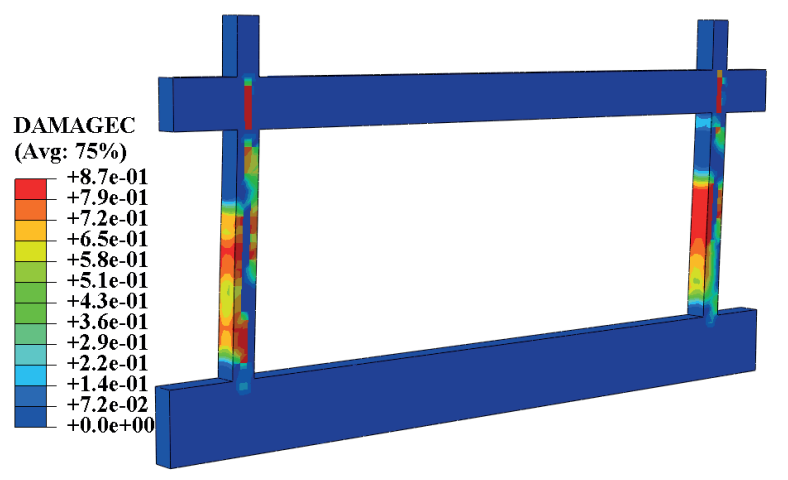

(a)

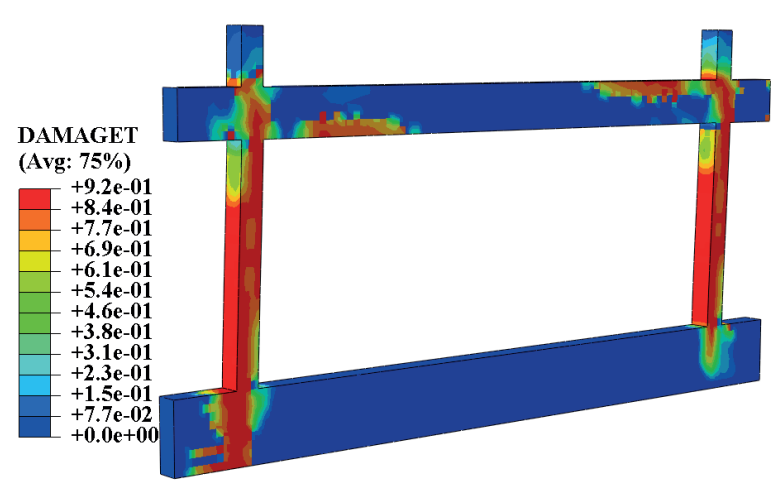

(b)

Fig. 12 Concrete damage contours in WC-BF-U2-E model: (a) Compressive $\left(d_{c}\right)$, and (b) Tension $\left(d_{t}\right)$

6 Performance Base Design

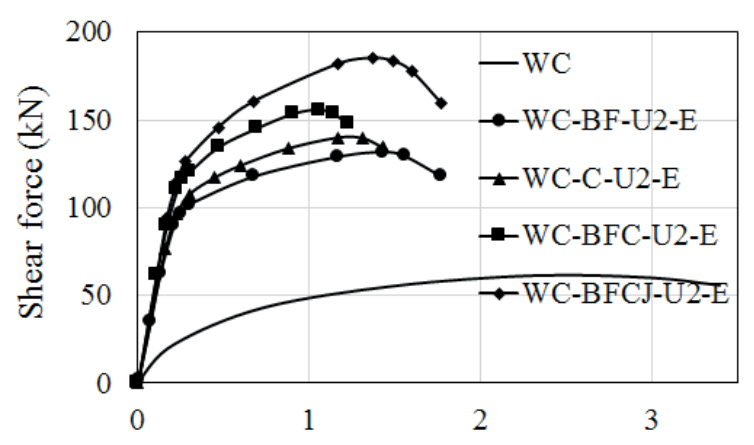

(a)

Drift ratio (\%)
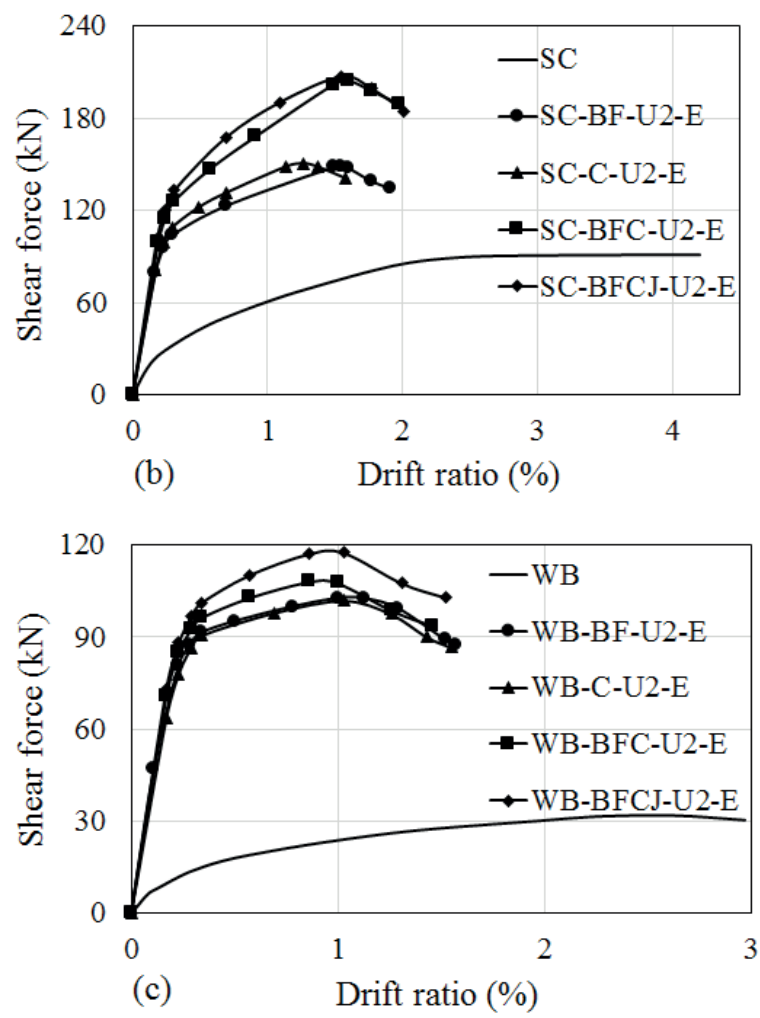

Fig. 13 Comparison of the pushover curves in: (a) No.1, (b) No.2 and (c) No.3 frames groups

the braced models in the initial range $(0-0.25$ drift $)$ has increased by an average of 4 times. Post-yield stiffness and the strain hardening behavior, which is useful for its response and reduces the system's deformation in the destruction state is apparent too. The energy dissipation and absorbed energy by the RC bare and braced frames are shown in Figs. 15 and 16, respectively.

Due to the lower yield drift in braced models, the braces are activated in a small drift value $(0.25-0.3 \%$ drift $)$ and increased an initial energy dissipation. This shows that, due to lateral forces such as earthquakes, the braced frames can dissipate the input energy in a smaller deformation range and limit the overall damage of the structure. The ductility index $(\mu)$, which is defined as the ratio of the 

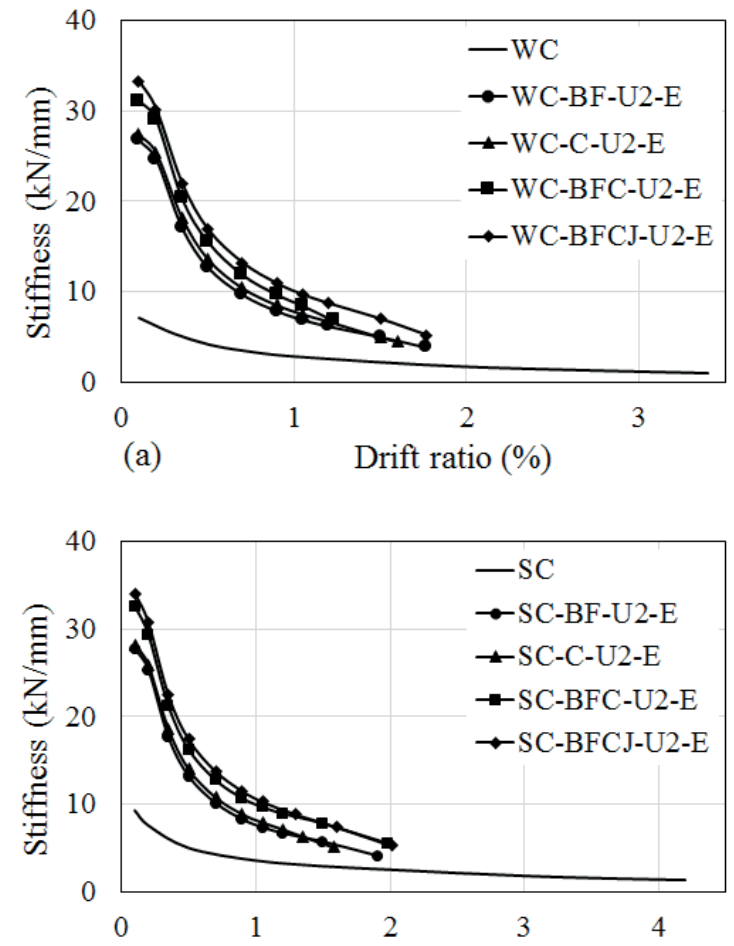

(b) Drift ratio (\%)

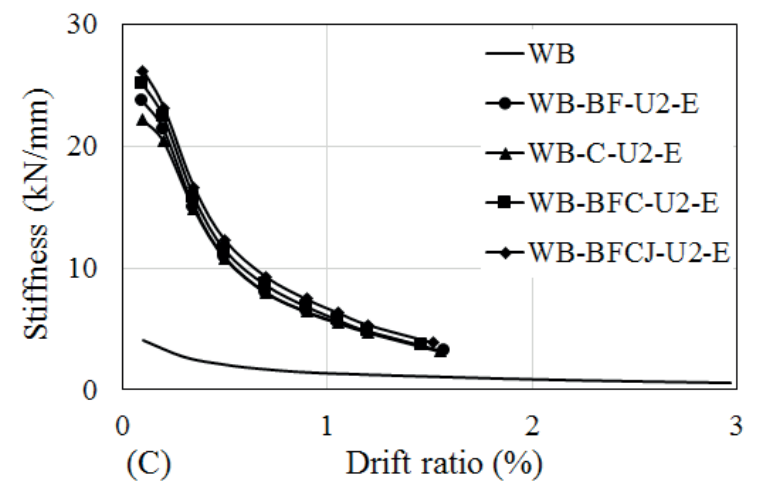

Fig. 14 Secant stiffness at different drift levels in: (a) No.1, (b) No.2 and (c) No.3 frames groups

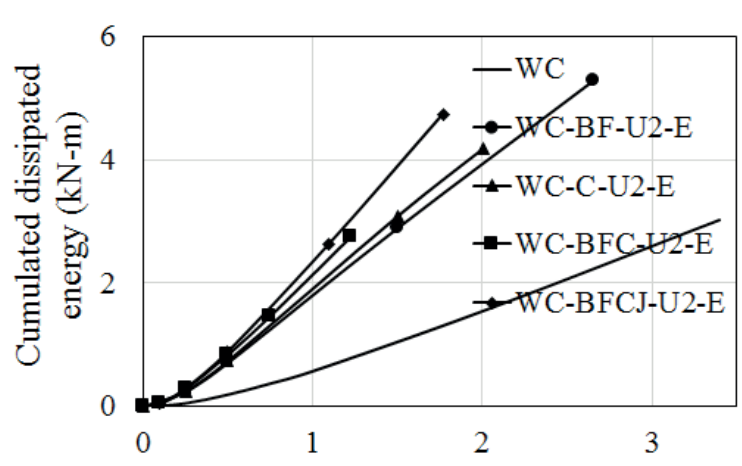

(a)

Drift ratio (\%)
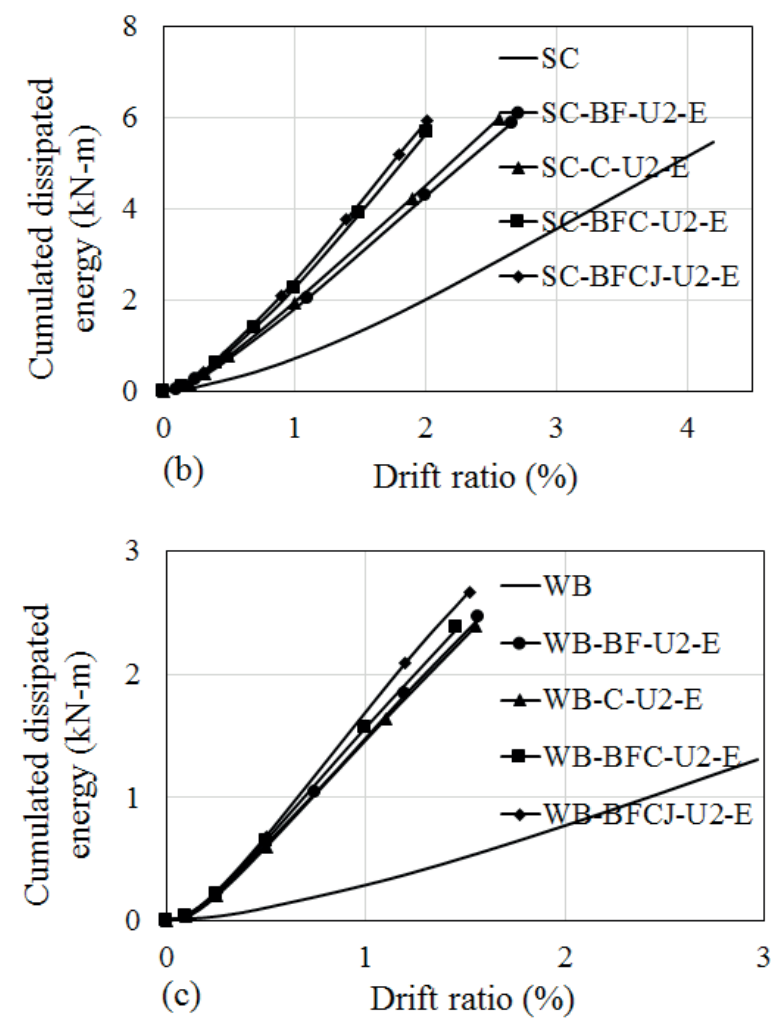

Fig. 15 Cumulative dissipated energy at different drift levels in: (a) No.1, (b) No.2 and (c) No.3 frames groups

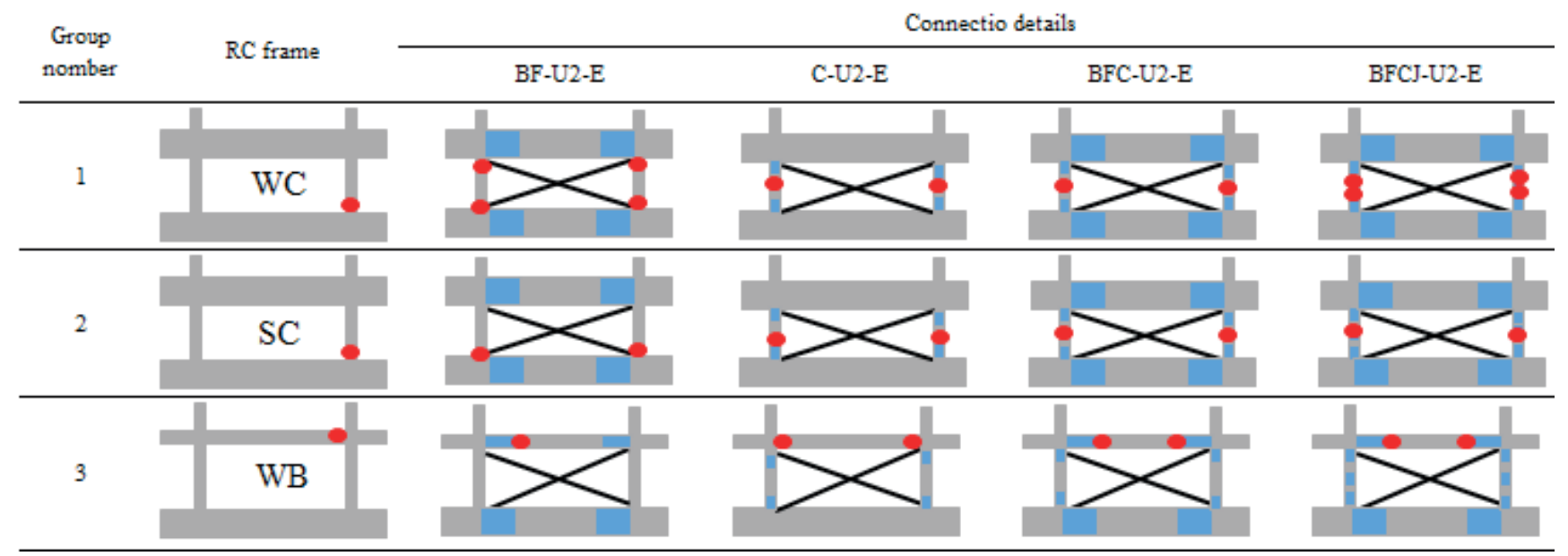

Fig. 16 Absorbed energy in No.1, 2 and 3 frames groups 
Table 5 Summary of displacement results in No.1,2 and 3 frames groups

\begin{tabular}{|c|c|c|c|c|c|}
\hline Group & Model name & $\begin{array}{l}\text { Yield Displacement } \\
(\mathrm{mm})\end{array}$ & $\begin{array}{l}\text { Ultimate Displacement } \\
\qquad(\mathrm{mm})\end{array}$ & $\begin{array}{c}\text { Ductility Ratio } \\
(\mu)\end{array}$ & $\frac{\mu_{\text {Bracing }}}{\mu_{R C}}$ \\
\hline \multirow[t]{5}{*}{1} & WC & 8.50 & 59.48 & 7.00 & 1.00 \\
\hline & WC-BF-U2-E & 5.05 & 30.93 & 6.12 & 0.88 \\
\hline & WC-C-U2-E & 5.10 & 28.08 & 5.51 & 0.79 \\
\hline & WC-BFC-U2-E & 4.95 & 21.57 & 4.36 & 0.62 \\
\hline & WC-BFCJ-U2-E & 5.70 & 30.22 & 5.30 & 0.76 \\
\hline \multirow[t]{5}{*}{2} & $\mathrm{SC}$ & 10.00 & 73.56 & 7.36 & 1.00 \\
\hline & SC-BF-U2-E & 5.50 & 33.47 & 6.09 & 0.83 \\
\hline & SC-C-U2-E & 5.30 & 27.67 & 5.22 & 0.71 \\
\hline & SC-BFC-U2-E & 6.30 & 34.65 & 5.50 & 0.75 \\
\hline & SC-BFCJ-U2-E & 6.10 & 35.25 & 5.78 & 0.79 \\
\hline \multirow[t]{5}{*}{3} & WB & 7.5 & 52.02 & 6.94 & 1.00 \\
\hline & WB-BF-U2-E & 4.43 & 27.51 & 6.21 & 0.89 \\
\hline & WB-C-U2-E & 4.6 & 27.21 & 5.92 & 0.85 \\
\hline & WB-BFC-U2-E & 4.37 & 25.62 & 5.86 & 0.84 \\
\hline & WB-BFCJ-U2-E & 4.5 & 26.54 & 5.90 & 0.85 \\
\hline
\end{tabular}

maximum lateral displacement of the frame to the corresponding displacement of the rebar's yield point, has been calculated for all the frames and is given in Table 5. In the No.3 frames group, yield points and plastic hinges perform in tensile rebar and lower part of the beam because of weaker beam than the columns according to the strong column-weak beam criteria. This is a disparity between this group and the other two groups. According to Fig. 17, due to increasing the load transfer through the brace to the beam and columns and increasing the flexural moment in the vicinity of the jacket, the plastic hinges have been transferred from the end of the members to the steel jacket's curb in all three groups.

The yield drift of a structural system is constant approximately, independent of the number of stories and its lateral strength and can be evaluated based on structural and

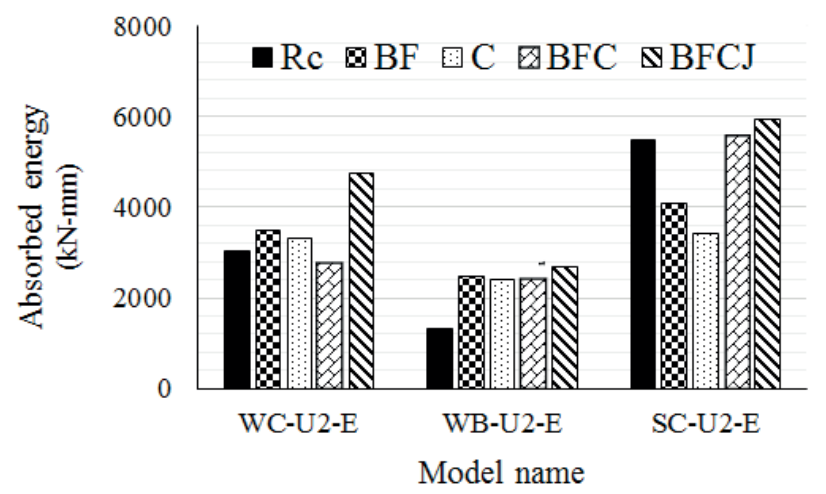

Fig. 17 Propagation of plastic hinges at failure state in the No.1,2 and 3 frames groups materials configuration. For a non-ductile RC frame with a relatively soft-story, the yield displacement is affected by the flexural response of the columns and can be estimated based on the characteristics of the material and the depth of the members. Therefore, in the next sections, the No.1 frames group, which is based on the experimental reference frame, will be the basis for future parametric studies.

\subsection{The gusset plate dimension review results}

Due to the width-span and dimensional ratio of the prototype frame, the concentration of beams, columns and braces requires the large gusset and jacket [8, 22]. Therefore, in this section, the effect of this parameter is evaluated. For this purpose, strengthening with 2UNP40 once done with eccentric form in No.4 frames group and another time with concentric form in No.5 frames group and results were compared. According to Fig. 18, increasing the dimensions of gusset plates, increases strength by $7 \%$ and decreases the final displacement by $30 \%$ on average in all models of these groups, and generally makes the frame more stiffness relatively, while the ductility ratio did not differ significantly. Figs. 19 and 20 show tangential stiffness and energy dissipation curves respectively, and Table 6 shows the ductility of these frames. As shown, the retrofit of vulnerable columns in WC-BFCJ-U4-C model, significantly improves the behavior of the braced frame, which is more noticeable than its eccentric form. The evolution of von Mises stresses in the WC-BFCJ-U4-E model is shown in Fig. 21. 


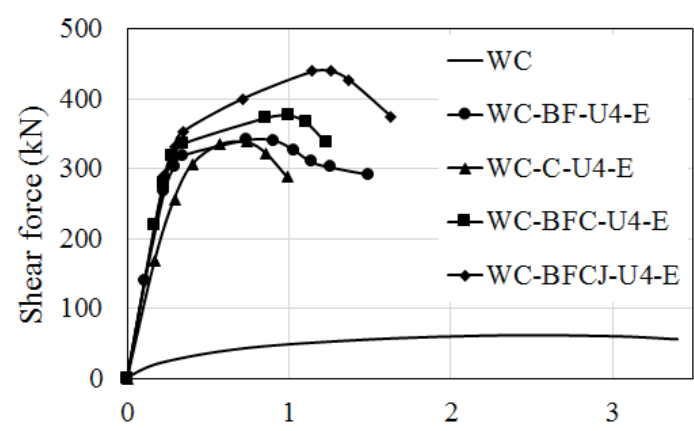

(a)

Drift ratio (\%)

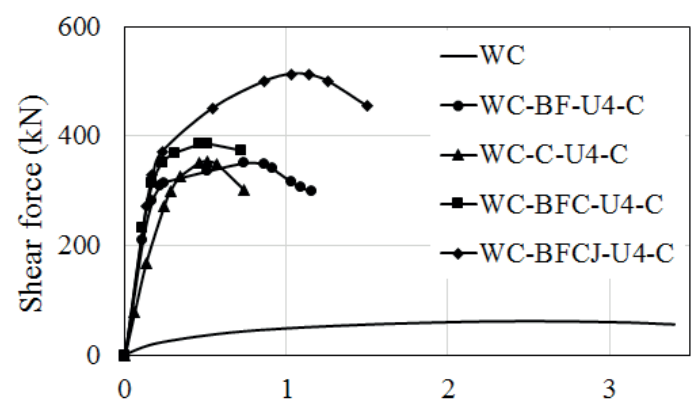

(b) Drift ratio (\%)

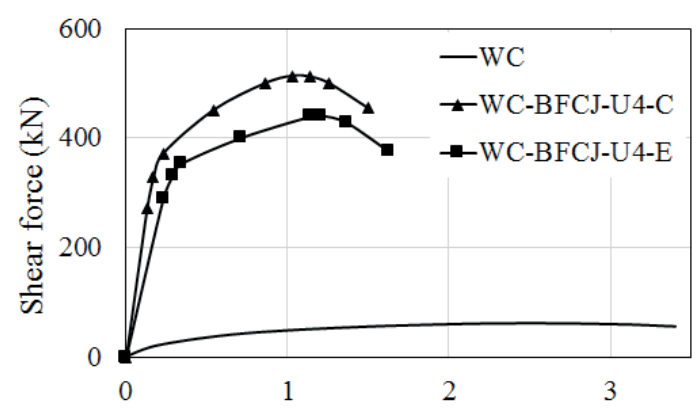

(c)

Drift ratio (\%)

Fig. 18 Comparison of the pushover curves between: (a) No.4, (b) No.5 and (c) No.4 and 5 frames group

\subsection{The cross section area of the brace review results}

In this section, the reference $\mathrm{RC}$ frame is strengthened with 2UNP100, then while comparing with 2UNP40 and 2UNP20, the effect of the brace cross-section area is evaluated in both of eccentric and concentric form. As shown in Fig. 22, with 4 times increase in the brace cross-section area in the WC-BFCJ-U4-E, the yield force $\left(P_{y}\right)$ and the ultimate load $\left(P_{u}\right)$ increase about 2.5 times compared with the WC-BFCJ-U2-E model and 7 times compared to the reference RC frame (WC). With an excessive increase of bracing sections in the No.6 frames group, the inability to withstand the overload applied to vulnerable columns is seen in this figure. Due to the increase in cross-sectional area, the braces yield in the No.4 frames group occurred at an average $300 \mathrm{kN}$ load. It also lingered and occurred in higher displacement compared to the No.1 frames group. In other

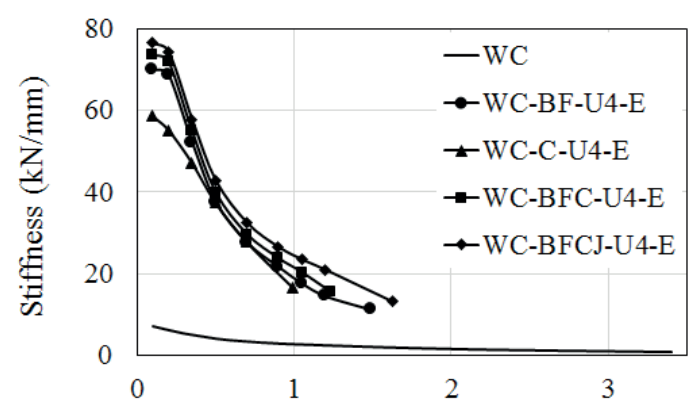

(a)

Drift ratio (\%)

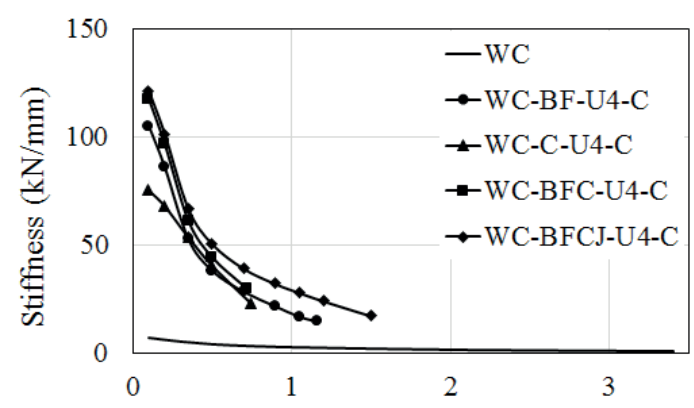

(b)

Drift ratio (\%)

Fig. 19 Secant stiffness at different drift levels in: (a) No.4 and (b) No.5 frames groups

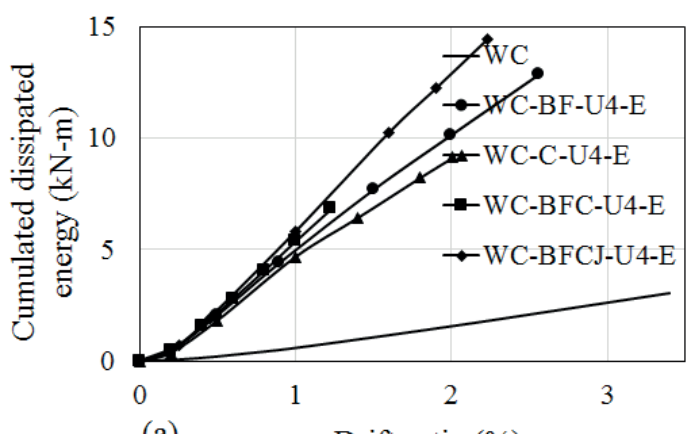

(a)

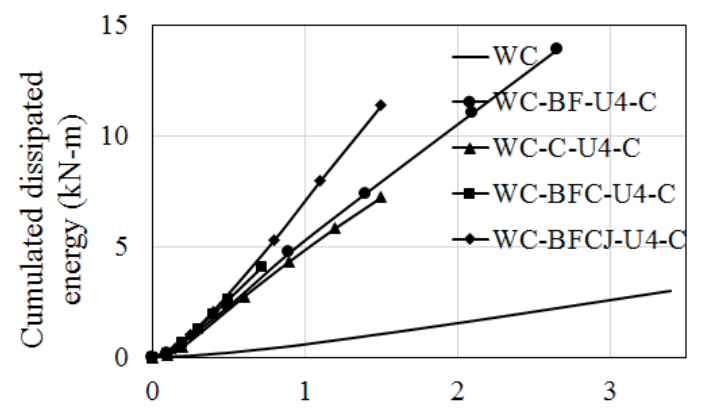

(b)

Drift ratio (\%)

Fig. 20 Cumulative dissipated energy at different drift levels in: (a) No.4 and (b) No.5 frames groups

words, in a given displacement, the amount of compressive and tensile strains of the braces decreases, but the column reinforcements yielding earlier. According to the analytical observations presented in Table 7, by increasing the brace 
Table 6 Summary of displacement results in No.4 and 5 frames groups

\begin{tabular}{|c|c|c|c|c|c|}
\hline Group & Model name & $\begin{array}{l}\text { Yield Displacement } \\
(\mathrm{mm})\end{array}$ & $\begin{array}{l}\text { Ultimate Displacement } \\
\qquad(\mathrm{mm})\end{array}$ & $\begin{array}{l}\text { Ductility Ratio } \\
\qquad(\mu)\end{array}$ & $\frac{\mu_{B r a c i n g}}{\mu_{R C}}$ \\
\hline \multirow{5}{*}{4} & WC & 8.50 & 59.48 & 7.00 & 1.00 \\
\hline & WC-BF-U4-E & 4.90 & 26.16 & 5.34 & 0.76 \\
\hline & WC-C-U4-E & 5.70 & 17.26 & 3.03 & 0.43 \\
\hline & WC-BFC-U4-E & 5.10 & 21.57 & 4.23 & 0.60 \\
\hline & WC-BFCJ-U4-E & 5.60 & 28.55 & 5.10 & 0.73 \\
\hline \multirow{5}{*}{5} & WC & 8.50 & 59.48 & 7.00 & 1.00 \\
\hline & WC-BF-U4-C & 3.40 & 20.33 & 5.98 & 0.85 \\
\hline & WC-C-U4-C & 4.40 & 12.96 & 2.95 & 0.42 \\
\hline & WC-BFC-U4-C & 3.20 & 12.64 & 3.95 & 0.56 \\
\hline & WC-BFCJ-U4-C & 4.20 & 26.30 & 6.26 & 0.89 \\
\hline
\end{tabular}

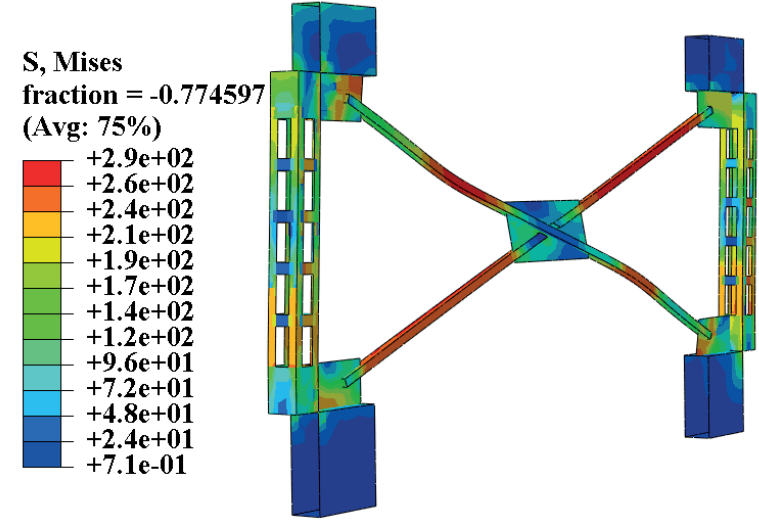

Fig. 21 Evolution of von Mises stresses (S,Mises) in the proposed simulation of steel members in the WC-BFCJ-U4-E model

section area 4 times, the concrete in the compressive zone of the right column's foot reaches its final strain earlier and the frame tolerates a lower displacement. In other words, it reaches $80 \%$ of the No.1 frames group and $40 \%$ of the referenced RC frame, which is due to increasing the flexural moment at critical points. The compressive damage of concrete is increased, especially during the mid-span of the beam and column, and the tensile damage is almost similar to that of No.1. The tangential stiffness and energy dissipation curves of No.6 frames group at different levels of drift are shown in Figs. 22 and 23, respectively.

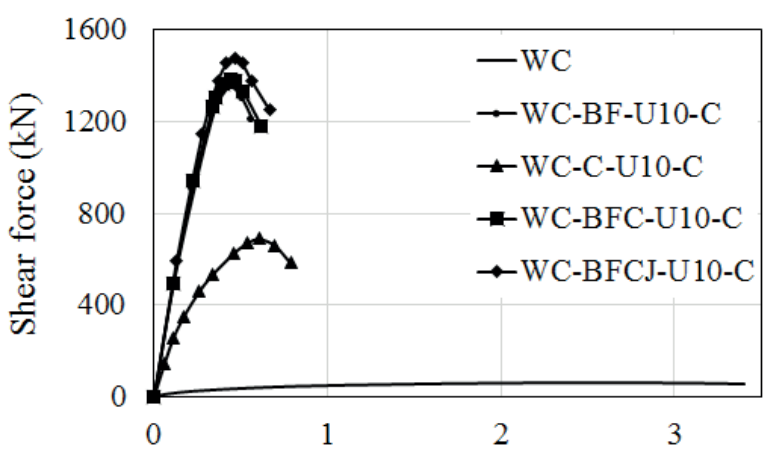

(a)

Drift ratio (\%)

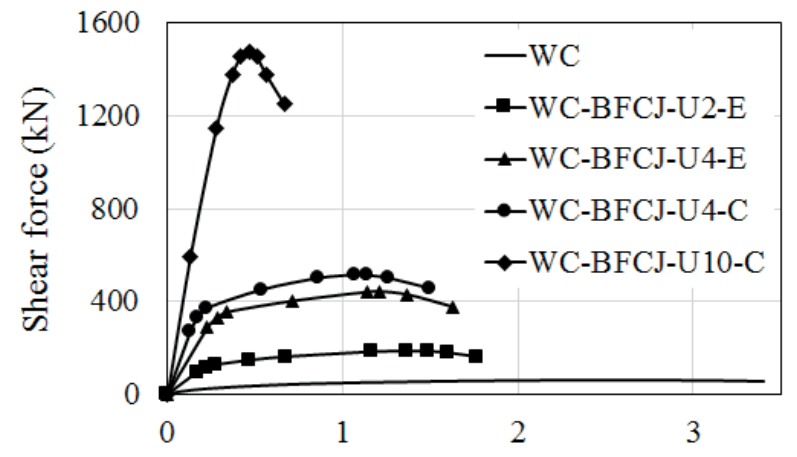

(b)

Drift ratio (\%)

Fig. 22 Comparison of the pushover curves in: (a) No. 6, (b) No.1,4,5 and 6 frames groups

Table 7 Summary of displacement results in No.6 frames group

\begin{tabular}{|c|c|c|c|c|c|}
\hline Group & Model name & $\begin{array}{l}\text { Yield Displacement } \\
(\mathrm{mm})\end{array}$ & $\begin{array}{l}\text { Ultimate Displacement } \\
\qquad(\mathrm{mm})\end{array}$ & $\begin{array}{l}\text { Ductility Ratio } \\
\qquad(\mu)\end{array}$ & $\frac{\mu_{\text {Bracing }}}{\mu_{R C}}$ \\
\hline \multirow{5}{*}{6} & WC & 8.50 & 59.48 & 7.00 & 1.00 \\
\hline & WC-BF-U10-C & 5.30 & 10.64 & 2.01 & 0.29 \\
\hline & WC-C-U10-C & 5.00 & 13.84 & 2.77 & 0.40 \\
\hline & WC-BFC-U10-C & 5.20 & 10.86 & 2.09 & 0.30 \\
\hline & WC-BFCJ-U10-C & 5.40 & 11.75 & 2.18 & 0.31 \\
\hline
\end{tabular}




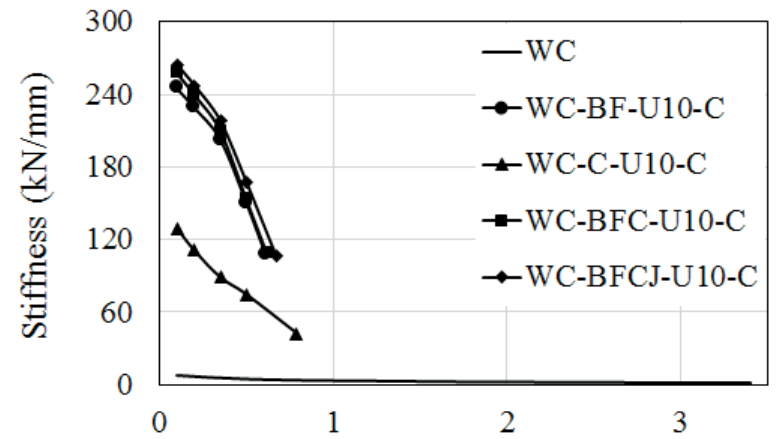

(a)

Drift ratio (\%)

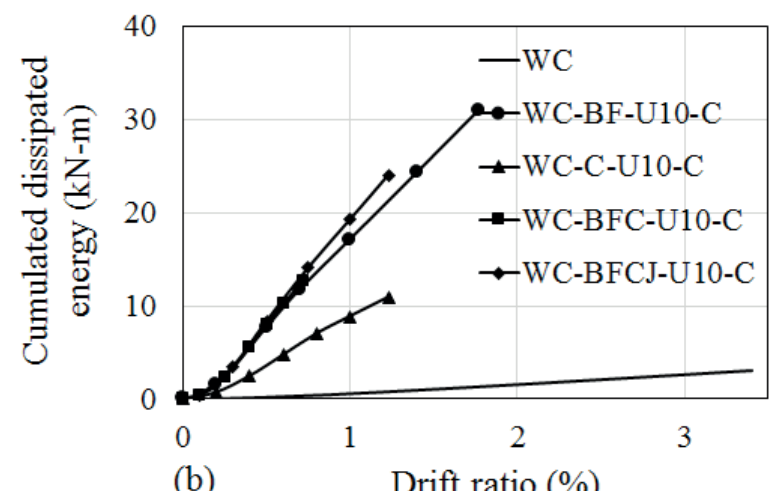

Fig. 23 Comparison of: (a) Second stiffness variations, (b) Cumulative dissipated energy at different drift levels in No.6 frames group

As shown in Fig. 24, with increasing the cross-section area in the No.6 frames group, plastic hinges are also observed in both of beam and column. In the No.1 and No.4 frames group, despite reaches the concrete in the compression column to its final strain, it seems that the frame system more resistant still in its final displacement. This is because of not completely formed the plastic hinges in the beam and redistribution of the flexural moment. However, in the No.6 frames group, with the complete formation of plastic hinges in the columns and beams, the loading capacity of the frame does not increase and remains constant. The absorbed energy by the RC and braced frames are shown in Fig. 25.

\section{Conclusions}

Based on static numerical analysis of referenced and strengthened RC frames with the direct internal connection of X-braces using steel jacket, under incremental lateral load as FEM in ABAQUS, noteworthy improvements in linear and nonlinear behavior and overall structural performance is undeniable. According to research, the following results have been obtained:

Strengthening of RC existing moment frames with steel bracing, increases load capacity and ultimate strength, initial and ultimate stiffness, as well as absorbed energy or the same area below the P. $\Delta$ curve of the frame. Such as the No. 2 frames group, which because the strong column-weak beam is the most standard group with more appropriate behavior concerning strengthening, has increased the above parameters by an average of 94, 413 and 87\%, respectively.

Although the stiffness of the linear and non-linear stage of load-displacement curves increases significantly in the braced RC frame compared to the bare frame, the stiffness of the strengthened frames in the linear stage does not differ much, However, their stiffness and ultimate strength increases in the nonlinear stages.

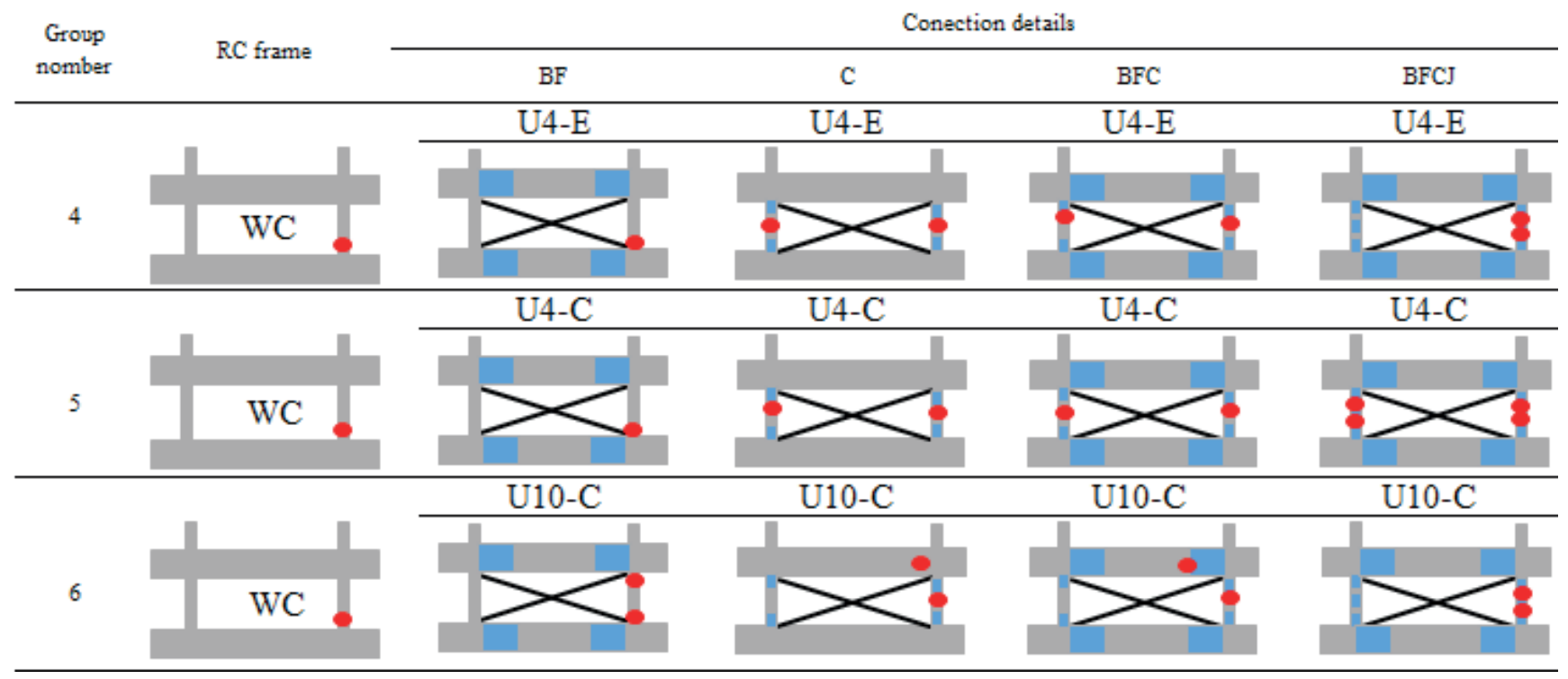

Fig. 24 Propagation of plastic hinges at failure state in the No.4,5 and 6 frames groups 


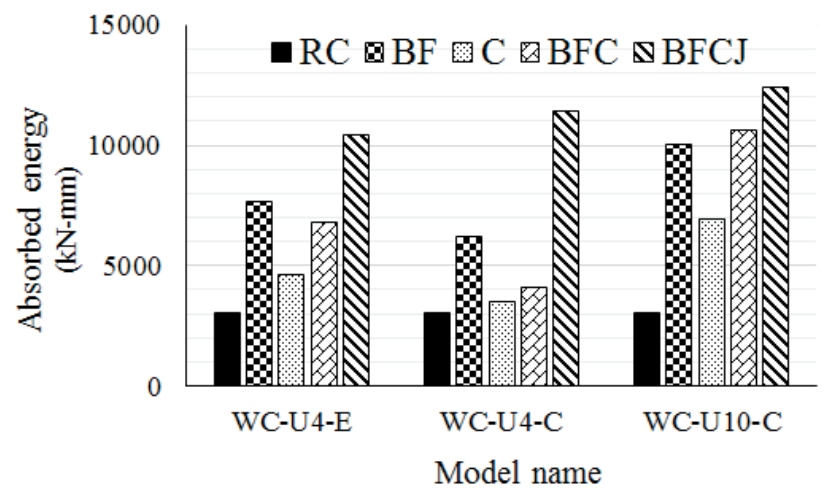

Fig. 25 Absorbed energy in No.4,.5 and 6 frames groups

The maximum lateral displacement and ductility of the strengthened moment frames compared to the RC frame have been reduced due to the performance of the connection. The average reduction in the No.2 frames group was $23 \%$.

General behavior of RC moment frames is influenced by its design strategy. So that choosing the right details for elements and reinforcement will reduce the plastic rotation and increase the energy absorption of the frame.

As the cross-section area of the braces increases, an increase in the yield and ultimate loads, as well as stiffness in the linear and nonlinear behavior of the frames, is evident. Moreover, as the internal stresses of the frame increase, the compressive strain of the concrete columns reaches its final value in less displacement, and as a result, the maximum lateral displacement and the ductility coefficient decrease. Therefore, choosing the right dimensions depends on the selected performance. As shown in this study, the No.5 frames group performed best, whereas we experienced a significant reduction in ductility in the No.6 frames group. This unbalanced performance causes us to witness no noticeable improvement in the general behavior of the strengthened frames.

Steel braces and jackets, increase the redundancy degree of the structure. The braces as the first defense system can depress lateral loads such as structural fuses. This method transfers the plastic hinges to the outside of the

\section{References}

[1] Khampanit, A., Leelataviwat, S., Kochanin, J., Warnitchai, P. "Energy-based seismic strengthening design of non-ductile reinforced concrete frames using buckling-restrained braces", Engineering Structures, 81, pp. 110-122, 2014.

https://doi.org/10.1016/j.engstruct.2014.09.033

[2] Kheyroddin, A., Khalili, A., Emami, E., Sharbatdar, M. K. "An innovative experimental method to upgrade performance of external weak RC joints using fused steel prop plus sheets", Steel and Composite Structures, 21(2), pp. 443-460, 2016.

https://doi.org/10.12989/scs.2016.21.2.443 panel zone and also stress concentration at the brace to the concrete intersection and severely destroys the concrete. This is seen in the No.3 frames group. In other frame groups, the location of the plastic hinges depends in part on the weakness of the columns and the vulnerability of the Available RC frame.

Due to the interaction between RC frame and steel braces in dual composite frames, the combined behavior is complex and depends on the relative strength and stiffness of the $\mathrm{RC}$ frame and bracing system. The combination of the reduced strength of the RC frame with the elastic-plastic resistance hardening of the brace is observed in the strengthened frame. So that in a frame with low bracing resistance, the behavior is affected by the response of the RC frame, and in frames with high bracing resistance, the behavior is affected by the brace response with the elastic-plastic strain hardening behavior. The results of this study showed that the Simultaneous connection of the brace to the beam and column causes the distribution of force between these members. In addition, strengthening these members for overload also has a positive effect. However, in this study, this strengthening was only carried out in the columns. which were weaker compared to the beam.

In most cases (except three) the compressive braces reach the yielding stage earlier than the tensile braces of each frame and the rate of increase in strain in them is about three times compared to the tensile braces during the frame displacement. However, as the cross-sectional area of the braces increases, the compressive and tensile strains become closer due to the reduction of the local buckling effect.

Finally, according to the results of the analytical study, if the goal is to strengthen the existing non-ductile $\mathrm{RC}$ frames with steel braces, increase lateral strength, stiffness and energy dissipation and reduce displacement, choosing a concentric X-brace is a good option, Of course, the reduction in ductility should be considered in design calculations.

[3] Sekiguchi, I., Okada, T., Murakami, M., Kumazawa, F., Horie, F., Seki, M. "Seismic Strengthening of An Existing Steel Reinforced Concrete City Office Building", In: Proceedings of The Ninth World Conference on Earthquake Engineering, Tokyo-Kyoto, Japan, 1988, pp. 439-444.

[4] Badoux, M., Jirsa, J. O. "Steel Bracing of RC Frames for Seismic Retrofitting", Journal of Structural Engineering, 116(1), pp. 55-74, 1990.

https://doi.org/10.1061/(asce)0733-9445(1990)116:1(55) 
[5] Pincheira, J. A., Jirsa, J. O. "Seismic Response of RC Frames Retrofitted with Steel Braces or Walls", Journal of Structural Engineering, 121(8), pp. 1225-1235, 1995.

https://doi.org/10.1061/(asce)0733-9445(1995)121:8(1225)

[6] Hemmati, A., Kheyroddin, A., Farzad, M. "Experimental Study of Reinforced Concrete Frame Rehabilitated by Concentric and Eccentric Bracing", Journal of Rehabilitation in Civil Engineering, 8(1), pp. 97-108, 2020

https://doi.org/10.22075/JRCE.2019.16055.1301

[7] Kheyroddin, A., Sepahrad, R., Saljoughian, M., Kafi, M. A. "Experimental evaluation of RC frames retrofitted by steel jacket, $\mathrm{X}$-brace and X-brace having ductile ring as a structural fuse", Journal of Building Pathology and Rehabilitation, 4(1), Article number: 11, 2019.

https://doi.org/10.1007/s41024-019-0050-z

[8] Kheyroddin, A., Gholhaki, M., Pachideh, G. "Seismic Evaluation of Reinforced Concrete Moment Frames Retrofitted with Steel Braces Using IDA and Pushover Methods in the Near-Fault Field", Journal of Rehabilitation in Civil Engineering, 7(1), pp. 159-173, 2019. https://doi.org/10.22075/jrce.2018.12347.1211

[9] Kheyroddin, A., Mortezaei, A., Mahmoudi, R. "Rehabilitation of RC Buildings using plastic hinge relocation with knee brace", Shrif Civil Engineering, 32-2(2.1), pp. 3-17, 2016. (in Persian)

[10] Mortezaei, A. "Behavior of steel unbonded brace in seismic strengthening of reinforced concrete buildings", Modares Civil Engineering Journal, 15(1), pp. 9-23, 2015. (in Persian)

[11] Rahimi, A., Maheri, M. R. "The effects of retrofitting RC frames by X-bracing on the seismic performance of columns", Engineering Structures, 173, pp. 813-830, 2018. https://doi.org/10.1016/j.engstruct.2018.07.003

[12] Maheri, M. R., Yazdani, S. "Design of steel brace connection to an RC frame using Uniform Force Method", Journal of Constructional Steel Research, 116, pp. 131-140, 2016. https://doi.org/10.1016/j.jcsr.2015.09.010

[13] Maheri, M. R., Hadjipour, A. "Experimental investigation and design of steel brace connection to RC frame", Engineering Structures, 25(13), pp. 1707-1714, 2003.

https://doi.org/10.1016/S0141-0296(03)00162-7
[14] Maheri, M. R., Kousari, R., Razazan, M. "Pushover tests on steel X-braced and knee-braced RC frames", Engineering Structures, 25(13), pp. 1697-1705, 2003.

https://doi.org/10.1016/S0141-0296(03)00150-0

[15] Massumi, A., Tasnimi, A. A. "Evaluation of response of reinforced concrete frames strengthened with steel bracing", presented at 3rd International Conference on Seismology and Earthquake Engineering (SEE3), Tehran, Iran, May, 17-19, 1999.

[16] Nateghi-A, F. "Seismic strengthening of eightstorey RC apartment building using steel braces", Engineering Structures, 17(6), pp. 455461, 1995.

https://doi.org/10.1016/0141-0296(95)00071-E

[17] Maheri, M. R., Sahebi, A. "Use of steel bracing in reinforced concrete frames", Engineering Structures, 19(12), pp. 1018-1024, 1997. https://doi.org/10.1016/S0141-0296(97)00041-2

[18] Ghobarah, A., Abou Elfath, H. "Rehabilitation of a reinforced concrete frame using eccentric steel bracing", Engineering Structures, 23(7), pp. 745-755, 2001 https://doi.org/10.1016/S0141-0296(00)00100-0

[19] Abou-Elfath, H., Ghobarah, A. "Behaviour of reinforced concrete frames rehabilitated with concentric steel bracing", Canadian Journal of Civil Engineering, 27(3), pp. 433-444, 2000. https://doi.org/10.1139/cjce-27-3-433

[20] Tagawa, Y., Aoki, H., Huang, T., Masuda, H. "Experimental study of new seismic strengthening method for existing RC structure", presented at 10th World Earthquake Engineering Conference, Madrid, Spain, July, 19-24, 1992.

[21] Youssef, M. A., Ghaffarzadeh, H., Nehdi, M. "Seismic performance of RC frames with concentric internal steel bracing", Engineering Structures, 29(7), pp. 1561-1568, 2007. https://doi.org/10.1016/j.engstruct.2006.08.027

[22] Massumi, A., Absalan, M. "Interaction between bracing system and moment resisting frame in braced RC frames", Archives of Civil and Mechanical Engineering, 13(2), pp. 260-268, 2013. https://doi.org/10.1016/j.acme.2013.01.004 